\title{
Particulate matter components and subclinical atherosclerosis: common approaches to estimating exposure in a Multi-Ethnic Study of Atherosclerosis cross-sectional study
}

Min Sun 1,2, Joel D Kaufman ${ }^{1,3,4}$, Sun-Young Kim¹, Timothy V Larson ${ }^{5}$, Timothy R Gould ${ }^{5}$, Joseph F Polak ${ }^{6}$, Matthew J Budoff', Ana V Diez Roux ${ }^{8}$ and Sverre Vedal ${ }^{1 *}$

\begin{abstract}
Background: Concentrations of outdoor fine particulate matter $\left(\mathrm{PM}_{2.5}\right)$ have been associated with cardiovascular disease. $\mathrm{PM}_{2.5}$ chemical composition may be responsible for effects of exposure to $\mathrm{PM}_{2.5}$.

Methods: Using data from the Multi-Ethnic Study of Atherosclerosis (MESA) collected in 2000-2002 on 6,256 US adults without clinical cardiovascular disease in six U.S. metropolitan areas, we investigated cross-sectional associations of estimated long-term exposure to total $\mathrm{PM}_{2.5}$ mass and $\mathrm{PM}_{2.5}$ components (elemental carbon [EC], organic carbon $[\mathrm{OC}]$, silicon and sulfur) with measures of subclinical atherosclerosis (coronary artery calcium [CAC] and right common carotid intima-media thickness [CIMT]). Community monitors deployed for this study from 2007 to 2008 were used to estimate exposures at baseline addresses using three commonly-used approaches: (1) nearest monitor (the primary approach), (2) inverse-distance monitor weighting and (3) city-wide average.

Results: Using the exposure estimate based on nearest monitor, in single-pollutant models, increased OC (effect estimate [95\% Cl] per IQR: $35.1 \mu \mathrm{m}$ [26.8, 43.3]), EC (9.6 $\mu \mathrm{m}$ [3.6,15.7]), sulfur $(22.7 \mu \mathrm{m}[15.0,30.4])$ and total PM 2.5 $(14.7 \mu \mathrm{m}[9.0,20.5])$ but not silicon $(5.2 \mu \mathrm{m}$ [-9.8,20.1]), were associated with increased CIMT; in two-pollutant models, only the association with OC was robust to control for the other pollutants. Findings were generally consistent across the three exposure estimation approaches. None of the PM measures were positively associated with either the presence or extent of CAC. In sensitivity analyses, effect estimates for $\mathrm{OC}$ and silicon were particularly sensitive to control for metropolitan area.

Conclusion: Employing commonly-used exposure estimation approaches, all of the $\mathrm{PM}_{2.5}$ components considered, except silicon, were associated with increased CIMT, with the evidence being strongest for OC; no component was associated with increased CAC. PM 2.5 chemical components, or other features of the sources that produced them, may be important in determining the effect of PM exposure on atherosclerosis. These cross-sectional findings await confirmation in future work employing longitudinal outcome measures and using more sophisticated approaches to estimating exposure.
\end{abstract}

Keywords: Atherosclerosis, Cardiovascular diseases, Coronary artery disease, Air pollution, Particulate matter

\footnotetext{
* Correspondence: svedal@uw.edu

'Department of Environmental and Occupational Health Sciences, University of Washington School of Public Health, 4225 Roosevelt Way NE, \#100, Seattle, WA 98105, USA

Full list of author information is available at the end of the article
} 


\section{Background}

Epidemiological studies have linked elevated levels of fine particulate matter $\left(\mathrm{PM}_{2.5}\right)$ air pollution to an increased risk of cardiovascular mortality and morbidity [1]. $\mathrm{PM}_{2.5}$ represents a heterogeneous mixture of particles generated by many sources. The U.S. National Research Council has emphasized the importance of identifying characteristics of PM that contribute to its toxicity [2]. However, there is little consistent evidence as to whether some chemical components or sources of $\mathrm{PM}_{2.5}$ are associated with greater risks. In cohort studies, Pope et al. [3] and Dockery et al. [4] both reported that long-term exposure to $\mathrm{PM}_{2.5}$ sulfate was associated with cardiopulmonary mortality. Ostro et al. also provided evidence that long-term exposures to $\mathrm{PM}_{2.5}$ and several $\mathrm{PM}_{2.5}$ components (EC, OC, sulfate, etc.) were associated with increased risks of all-cause and cardiopulmonary mortality [5].

Most cohort studies on air pollution and cardiovascular health have been limited to estimating effects on cardiovascular events such cardiovascular death or incidence of cardiovascular disease [4,6-13]. Recently, cardiovascular cohorts have employed subclinical measures of cardiovascular disease, such as carotid intima-media thickness (CIMT), coronary artery calcium (CAC), and the anklebrachial index (ABI) [14-16] that are predictive of future clinical cardiovascular events [17].

The Multi-Ethnic Study of Atherosclerosis (MESA) is a cohort study in six U. S. metropolitan areas involving four racial-ethnic groups (non-Hispanic white, African American, Hispanic and Chinese) designed to assess the prevalence, correlates and progression of subclinical cardiovascular disease [18]. The Multi-Ethnic Study of Atherosclerosis and Air Pollution (MESA Air) is an ancillary study to MESA designed to investigate effects of individual-level exposures to ambient $\mathrm{PM}_{2.5}$ and trafficassociated pollutants on subclinical and clinical cardiovascular disease in the MESA cohort [19]. Individual-level exposures will be estimated incorporating cohort-specific pollutant monitoring, spatio-temporal modeling, and eventually participant time-activity information. One part of the Health Effect Institute's National Particle Components Toxicity (NPACT) Initiative is an ancillary study to MESA Air designed to use cohort-specific $\mathrm{PM}_{2.5}$ speciated monitoring data to identify the role of chemical components of $\mathrm{PM}_{2.5}$. Here we report findings based on MESA, MESA Air and NPACT on the cross-sectional associations between two subclinical measures, CIMT and CAC, and exposure to both $\mathrm{PM}_{2.5}$ and $\mathrm{PM}_{2.5}$ chemical components. We employ more commonly-used approaches to estimating exposure than those that will ultimately be used with an eye to being able to assess the impact in this planned paper on the health findings of using more sophisticated exposure estimates.

\section{Methods}

\section{Subjects and geocoding}

The original MESA cohort consisted of 6,814 men and women aged 45-84 years who were free of clinical cardiovascular disease at the baseline examination in 2000-2002. Detailed MESA eligibility criteria are available online (http://www.mesa-nhlbi.org). Individuals were recruited from communities near six field centers: Baltimore, Maryland; Chicago, Illinois; Forsyth County (Winston-Salem), North Carolina; Los Angeles County, California; New York City, New York; and St. Paul, Minnesota. Details of the sampling plan have been previously reported [18]. The present analyses are based on health data collected at the baseline visit (July 2000August 2002). The study was reviewed and approved by the Institutional Review Board of the University of Washington Human Subjects Division. Institutional review board approval was also granted at each study site and written informed consent was obtained from all participants.

Participants' residential addresses at baseline were assigned geographic coordinates using ArcGIS 9.1 software (ESRI, Redlands, CA). Addresses were manually cleaned prior to geocoding, and matches with a geocoding score less than or equal to $80 \%$ were checked manually for accuracy. Of the 6,814 MESA cohort members at baseline, 6,256 consented to geocoding and were successfully geocoded.

\section{Outcome and risk factor data}

Subclinical cardiovascular disease measures of CIMT and CAC were used as the primary endpoints. Trained technicians obtained images on supine study participants of the right common carotid artery using high resolution B-mode ultrasound (Logiq 700, $13 \mathrm{MHz}$; GE Medical Systems, Waukesha, Wisconsin). Images were obtained over a distance of $10 \mathrm{~mm}$ proximal to the common carotid bulb and transferred from each study center to Tufts Medical Center for measurement of CIMT. The mean far wall thickness of the right common carotid, retrospectively gated to end-diastole, was used for the analysis [20]. CAC was measured by chest computed tomography $(\mathrm{CT})$ using a cardiac-gated electron beam computed tomography scanner (Imatron C-150; Imatron, San Francisco, California) at three field centers (Chicago, Los Angeles County, New York) and a retrospectively gated multi-detector row computed tomography system (Lightspeed, General Electric Medical Systems, Waukesha, Wisconsin; or Volume Zoom, Siemens, Erlanger, Germany) at the other three field centers (Baltimore, Winston-Salem, St. Paul) [21]. All scans used phantoms of known physical calcium concentration. Two CT scans were obtained for each participant. Scans were read centrally at the HarborUCLA Research and Education Institute in Torrance, 
California. The mean Agatston score [22] of the two scans was used for the analysis. The presence of CAC was defined as an Agatston score greater than zero.

Data on demographics, lifestyle characteristics, cardiovascular risk factors, medical history, and use of medications were obtained from detailed questionnaires.

\section{Air pollution exposure estimation}

Details of the MESA Air monitoring site locations and protocol have been reported previously [23]. Figure 1 shows MESA Air fixed monitoring site locations in the six MESA areas. In general, one monitor was collocated with a U. S. Environmental Protection Agency Chemical Speciation Network (CSN) $\mathrm{PM}_{2.5}$ monitor, one near a roadway, and one in an area near a large concentration of study participant residences. Specifically, five monitors were sited in Los Angeles County, CA; three monitors in St. Paul, MN; four monitors in Forsyth County, NC; five monitors in Chicago, IL; four monitors in Baltimore, MD; and two monitors in New York City, NY. The location for these sites included libraries, schools, or other buildings that were in participant-dense areas underrepresented by the existing CSN. MESA Air and NPACT monitoring consisted of two-week samples of $\mathrm{PM}_{2.5}$ obtained on Teflon and quartz filters for every two weeks during the study period (see below). In addition to measurement of $\mathrm{PM}_{2.5}$ mass, Teflon filters underwent X-ray fluorescence (XRF) for trace elements and metals (Cooper Environmental Services, Portland, OR); EC and OC were measured on the quartz filters using the IMPROVE-A /thermal optical reflectance (TOR) method (Sunset Laboratory Inc., Tigard, OR). Monitoring at MESA Air sites began in July, 2005 and ended in August 2009; quartz filters were only deployed from April 2007 through August 2008. Data from the 50-week period from May 2, 2007 to April 16, 2008 was used for this analysis in order to obtain a near full year of data on all components. To deal with outliers, the mean for each monitoring site over that period was calculated as the 10 percent trimmed mean (i. e., the top and bottom 5 percent of data were excluded for the calculation of the mean). The following $\mathrm{PM}_{2.5}$ component concentrations were included in this analysis: elemental carbon [EC], organic carbon [OC], silicon and sulfur. $\mathrm{EC}$ and $\mathrm{OC}$ were selected as reflecting combustion sources, silicon as an indicator of crustal dust and sulfur as an indicator of sulfate, a secondary aerosol.

Three different approaches were used to estimate study participant exposure to $\mathrm{PM}_{2.5}$ components within each of the six areas corresponding to field centers: (1) the annual average concentration of the two-week measurements at the monitor nearest to each study participant's residence at the baseline examination ("nearest monitor"); (2) inverse distance weighting (IDW) of all annual average monitor concentrations in each area relative to each subject's residence; and (3) city-wide average concentrations based on all monitors within each area.

For all three approaches, participants within each area residing within 100 meters of either an A1 road (primary

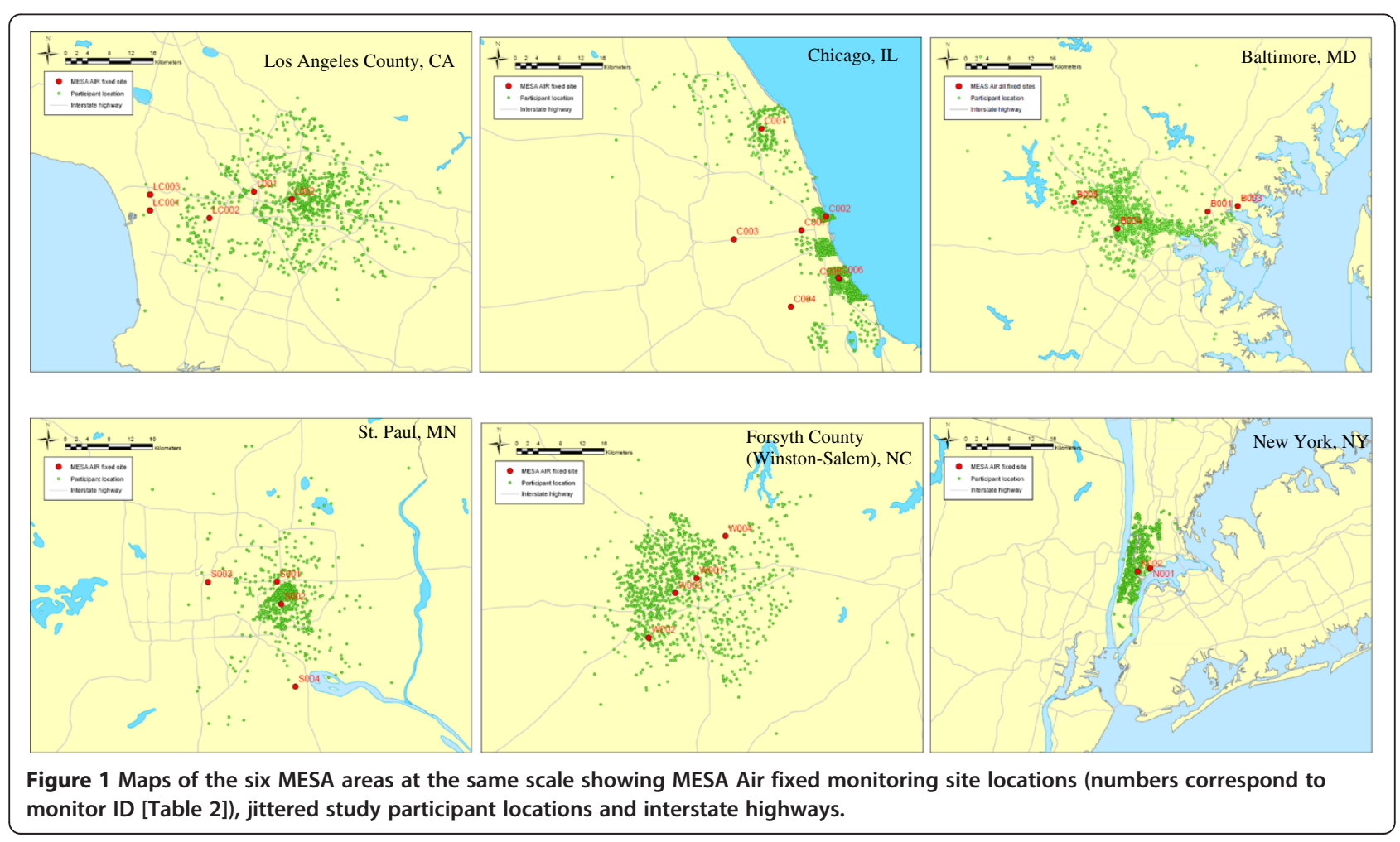


limited access or interstate highway) or an A2 road (primary US or state highway, without limited access), or within 50 meters of an A3 road (secondary state or county highway), were considered "near roadway" participants. Because $\mathrm{PM}_{2.5}$ and EC concentrations are strongly influenced by proximity to major roadways, for all approaches, near roadway participants were assigned the average $\mathrm{PM}_{2.5}$ and $\mathrm{EC}$ concentrations measured at that area's MESA Air roadside monitor. The roadside monitors were not used in calculating the $\mathrm{PM}_{2.5}$ and EC exposures of participants not living close to an A1, A2 or A3 road. For OC, silicon and sulfur, roadside monitors were included in the calculations for all three of the exposure estimation methods.

To obtain information on temporal trends, $\mathrm{PM}_{2.5}$ component data were obtained from the Health Effects Institutes (HEI) Air Quality Database website (https://hei.aer.com/ login.php) for 2002 and 2007. Because there were no CSN $\mathrm{PM}_{2.5}$ component data in St. Paul, Minneapolis data were used instead.

\section{Statistical analysis}

Multiple linear regression was used to estimate the associations between $\mathrm{PM}_{2.5}$ measures and CIMT and CAC (among persons with Agatston scores greater than zero). Agatston scores were analyzed after log transformation. Relative risk regression was used to estimate the associations between $\mathrm{PM}_{2.5}$ measures and the presence of CAC (Agatston scores $>0$ ) [24]. All measures of association were expressed per inter-quartile range (IQR) of each concentration measure.

Covariates in our base model (Model 1) included age, gender, and race/ethnicity. Covariates included in our primary health model (Model 2) were selected based on the Framingham Risk Score [25]. In addition to Model 1 covariates, Model 2 included total cholesterol, HDL cholesterol, smoking status, hypertension, and lipid lowering medication. An extended set of covariates was included in Model 3 that added potential risk factors not included in the Framingham Risk Score: level of education, income, waist circumference, body surface area, body mass index (BMI) and squared BMI, diabetes, LDL cholesterol and triglycerides. In Model 4, metropolitan areas were added as indicator variables to our primary model (Model 2).

Race/ethnicity was categorized as white non-Hispanic of European ancestry, Chinese, African American, or Hispanic, as reported by the study participants. BMI, total cholesterol, HDL cholesterol, LDL cholesterol, triglycerides, waist circumference and body surface area were included as continuous variables. Cigarette smoking status was categorized as never, former or current smoker. Annual family income was categorized into 5 categories. Education was classified as: high school not completed, high school completed, some college but no degree, or completed bachelor's degree or more. Current use of lipid-lowering medications was classified as either some or none. Diabetes was categorized as not diabetic, impaired fasting glucose (defined fasting glucose $=5.5$ $6.9 \mathrm{mmol} / \mathrm{L}(100-125 \mathrm{mg} / \mathrm{dL}))$, untreated diabetes and treated diabetes. Diabetes was defined as fasting glucose of $\geq 7.0 \mathrm{mmol} / \mathrm{L}$ ( $\geq 126 \mathrm{mg} / \mathrm{dL}$ ) or use of hypoglycemic medication. Hypertension was defined as systolic blood pressure $\geq 140 \mathrm{mmHg}$, diastolic blood pressure $\geq 90$ $\mathrm{mmHg}$ or taking antihypertensive medications.

Models using the nearest monitor concentration estimates and the primary set of health covariates (Model 2) were considered as our primary analytic models. Sensitivity analysis included comparing findings across the four sets of covariate models and the three alternative exposure measures, as well as assessing estimates from selected two-pollutant models and models for CIMT that controlled for ultrasound sonographer.

All data analyses were performed using R 2.12.2 [26].

\section{Results}

\section{Subject characteristics}

Mean age of the study participants was 62 years, 47.5 percent were male, and 39.1 percent were non-Hispanic white, 11.7 percent Chinese, 27.4 percent African American, and 21.7 percent Hispanic. Additional characteristics of the study sample are shown in Table 1 . The prevalence of current smoking was low (12.7\%), and approximately half of the cohort reported never having smoked.

Median CIMT was $0.84 \mathrm{~mm}$ (IQR $0.23 \mathrm{~mm}$ ) in the 6,183 study participants with CIMT. Forty nine percent of the 6,256 participants with a CAC measurement had an Agatston score greater than 0; among those, the median score was 86.0 Agatston units (IQR 270.5).

Two hundred and eight subjects (3.3\%) lived within 100 meters of an A1 road, 243 (3.9\%) with 100 meters of an A2 road, and 1,459 (23.3\%) within 50 meters of an A3 road. A total of 1,774 subjects $(28.4 \%)$ were therefore classified as living close to a major roadway. Using the criteria for living close to a major roadway, the following in each area lived close to a major roadway: $18.5 \%$ in Forsyth County (Winston-Salem), 59.5\% in New York, $20.8 \%$ in Baltimore, $22.8 \%$ in St. Paul, $31.2 \%$ in Chicago, and $18.1 \%$ in Los Angeles County. Among those not living close to a major roadway, median distance to the nearest MESA Air monitor was $4.1 \mathrm{~km}$ (IQR 4.3); 90.3\% of the participants resided within $10 \mathrm{~km}$ of a MESA Air monitor.

\section{$\mathrm{PM}_{2.5}$ and $\mathrm{PM}_{2.5}$ component concentrations}

Table 2 shows $\mathrm{PM}_{2.5}$ and $\mathrm{PM}_{2.5}$ component annual average concentrations $\left(\mu \mathrm{g} / \mathrm{m}^{3}\right)$ by metropolitan area and monitor site. In general, $\mathrm{PM}_{2.5}$ and $\mathrm{EC}$ concentrations 
Table 1 Participant characteristics (total $\mathrm{N}=6,256$ ) at the baseline examination 2000-2002

\begin{tabular}{|c|c|c|c|c|c|}
\hline & $\mathrm{N}$ & $\%$ & & N/mean & $\% / S D$ \\
\hline Gender & & & Diabetes & & \\
\hline Male & 2974 & 47.5 & Normal & 4635 & 74.1 \\
\hline Female & 3282 & 52.5 & $\mathrm{IFG}^{*}$ & 855 & 13.7 \\
\hline Age(years) & & & Treated diabetes & 157 & 2.5 \\
\hline $45-54$ & 1828 & 29.2 & Untreated diabetes & 589 & 9.4 \\
\hline $55-64$ & 1755 & 28.1 & Missing & 20 & 0.3 \\
\hline $65-74$ & 1838 & 29.4 & Education & & \\
\hline $75-84$ & 835 & 13.3 & Less than high school graduate & 1057 & 16.9 \\
\hline Race-ethnicity & & & High school graduate & 1135 & 18.1 \\
\hline White & 2449 & 39.1 & Some college & 1776 & 28.4 \\
\hline Chinese & 735 & 11.7 & College graduate or higher & 2269 & 36.3 \\
\hline Black & 1714 & 27.4 & Missing & 19 & 0.3 \\
\hline Hispanic & 1358 & 21.7 & Lipid lowering medication & & \\
\hline Income (\$/year) & & & No & 5238 & 83.7 \\
\hline$<12,000$ & 655 & 10.5 & Yes & 1015 & 16.2 \\
\hline $12,000-24,999$ & 1161 & 18.6 & Missing & 3 & 0.05 \\
\hline $25,000-49,999$ & 1748 & 27.9 & Hypertension & & \\
\hline $50,000-74,999$ & 1048 & 16.8 & No & 3504 & 56.0 \\
\hline$\geq 75,000$ & 1410 & 22.5 & Yes & 2752 & 44.0 \\
\hline missing & 234 & 3.7 & MESA area & & \\
\hline Cigarette smoking & & & Forsyth County (Winston-Salem) & 999 & 16.0 \\
\hline Never & 3145 & 50.3 & New York & 1021 & 16.3 \\
\hline Former & 2299 & 36.7 & Baltimore & 975 & 15.6 \\
\hline Current & 794 & 12.7 & St. Paul & 982 & 15.7 \\
\hline Missing & 18 & 0.3 & Chicago & 1088 & 17.4 \\
\hline$\left.B M\right|^{*}$ & & & Los Angeles County & 1191 & 19.0 \\
\hline$<23$ & 1796 & 28.7 & Total choleterol (mg/dl) & 194.1 & 35.4 \\
\hline $23-27.5$ & 2459 & 39.3 & HDL choleterol (mg/dl) & 50.9 & 14.7 \\
\hline $27.6-40$ & 1777 & 28.4 & LDL choleterol (mg/dl) & 117.2 & 31.2 \\
\hline \multirow[t]{3}{*}{$>40$} & 224 & 3.6 & Triglycerides (mg/dl) & 131.0 & 86.6 \\
\hline & & & Waist circumference $(\mathrm{cm})$ & 98.0 & 14.3 \\
\hline & & & Body surface area & 1.9 & 0.2 \\
\hline
\end{tabular}

* BMI=body mass index; IFG=impaired fasting glucose.

were highest at the roadside monitors. Table 3 shows median (IQR) study subject $\mathrm{PM}_{2.5}$ and component concentrations for the three exposure metrics. Mean $\mathrm{PM}_{2.5}$ concentrations for the six study areas based on nearest monitor ranged from $16.2 \mu \mathrm{g} / \mathrm{m}^{3}$ (Los Angeles County) to $10.3 \mu \mathrm{g} / \mathrm{m}^{3}$ (St. Paul); EC ranged from $2.7 \mu \mathrm{g} / \mathrm{m}^{3}$ (New York City) to $0.7 \mu \mathrm{g} / \mathrm{m}^{3}$ (St. Paul); OC ranged from $2.5 \mu \mathrm{g} / \mathrm{m}^{3}$ (Winston-Salem) to $1.6 \mu \mathrm{g} / \mathrm{m}^{3}$ (St. Paul); silicon ranged $0.15 \mu \mathrm{g} / \mathrm{m}^{3}$ (Los Angeles County) to 0.08 $\mu \mathrm{g} / \mathrm{m}^{3}$ (Baltimore); and sulfur ranged from $1.7 \mu \mathrm{g} / \mathrm{m}^{3}$ (Baltimore) to $0.9 \mu \mathrm{g} / \mathrm{m}^{3}$ (St. Paul) (Figure 2). Strong correlations (Pearson's correlation coefficient greater than 0.70) were present for $\mathrm{PM}_{2.5}$ and $\mathrm{EC}$ (0.74 for nearest monitor), and $\mathrm{OC}$ and sulfur ( 0.80 for city-wide average). Figure 2 also shows standard deviations of the means of the three exposure predictions for each $\mathrm{PM}_{2.5}$ component by city and for all cities combined. The within-city variability is markedly less than the variability for all cities combined.

In order to assess stability of $\mathrm{PM}_{2.5}$ and $\mathrm{PM}_{2.5}$ component concentrations over time, we used data from the CSN monitoring network. Figure 3 shows the correspondence between mean $\mathrm{PM}_{2.5}$ and $\mathrm{PM}_{2.5}$ component concentrations from the CSN for 2002 and 2007 in the MESA areas with available CSN data. There was generally good correspondence between concentrations over that five-year span, except for silicon, which showed a decrease in four of the six MESA areas. 
Table $2 \mathrm{PM}_{2.5}$ and $\mathrm{PM}_{2.5}$ component annual average concentrations $\left(\mu \mathrm{g} / \mathrm{m}^{3}\right)$ by area and MESA Air monitor

\begin{tabular}{|c|c|c|c|c|c|c|c|}
\hline City & Monitor* & Type & $\mathrm{PM}_{2.5}{ }^{* *}$ & $\mathrm{EC}^{* *}$ & $\mathrm{OC}^{* *}$ & Silicon & Sulfur \\
\hline \multirow[t]{5}{*}{ LA County } & L001 & non-roadside & 16.3 & 2.0 & 2.6 & 0.15 & 1.18 \\
\hline & L002 & roadside & 16.8 & 2.1 & 2.4 & 0.16 & 1.22 \\
\hline & LCO01 & non-roadside & 13.4 & 1.5 & 1.6 & 0.13 & 1.20 \\
\hline & LCO02 & non-roadside & 15.3 & 1.6 & 2.2 & 0.14 & 1.23 \\
\hline & LCO03 & roadside & 13.3 & 1.4 & 1.4 & 0.12 & 1.18 \\
\hline \multirow[t]{5}{*}{ Chicago } & C001 & non-roadside & 12.2 & 1.2 & 1.7 & 0.10 & 1.13 \\
\hline & C002 & non-roadside & 13.7 & 1.3 & 1.8 & 0.13 & 1.19 \\
\hline & C004 & non-roadside & 14.6 & 1.6 & 2.0 & 0.10 & 1.31 \\
\hline & C006 & non-roadside & 13.8 & 1.3 & 1.8 & 0.12 & 1.26 \\
\hline & C007 & roadside & 15.5 & 1.7 & 2.1 & 0.12 & 1.30 \\
\hline \multirow[t]{4}{*}{ Baltimore } & B001 & roadside & 15.6 & 2.1 & 2.4 & 0.11 & 1.69 \\
\hline & B003 & non-roadside & 14.7 & 1.4 & 2.3 & 0.09 & 1.69 \\
\hline & B004 & non-roadside & 13.9 & 1.4 & 2.1 & 0.08 & 1.67 \\
\hline & B005 & non-roadside & 12.7 & 1.0 & 1.9 & 0.07 & 1.53 \\
\hline \multirow[t]{3}{*}{ St. Paul } & S001 & roadside & 11.0 & 1.1 & 1.9 & 0.12 & 0.87 \\
\hline & S002 & non-roadside & 10.2 & 0.7 & 1.6 & 0.11 & 0.85 \\
\hline & S003 & non-roadside & 10.5 & 0.8 & 1.7 & 0.11 & 0.83 \\
\hline \multirow[t]{2}{*}{ NY } & N001 & non-roadside & 13.2 & 2.3 & 1.9 & 0.11 & 1.46 \\
\hline & N002 & roadside & 15.4 & 3.0 & 1.9 & 0.15 & 1.36 \\
\hline Forsyth County & W001 & non-roadside & 13.2 & 1.5 & 2.6 & 0.09 & 1.62 \\
\hline \multirow[t]{3}{*}{ (Winston-Salem) } & W002 & non-roadside & 13.2 & 1.1 & 2.5 & 0.10 & 1.59 \\
\hline & W003 & roadside & 13.9 & 1.2 & 2.6 & 0.10 & 1.66 \\
\hline & W004 & non-roadside & 13.0 & 1.0 & 2.4 & 0.09 & 1.67 \\
\hline
\end{tabular}

* May 2, 2007 - Apr 16, 2008, see Figure 1.

** $\mathrm{PM}_{2.5}$, particulate matter less than or equal to $2.5 \mu \mathrm{m}$ in aerodynamic diameter; EC, elemental carbon; OC, organic carbon.

\section{CIMT}

Table 4 shows estimates of effects of $\mathrm{PM}_{2.5}$ and $\mathrm{PM}_{2.5}$ components on CIMT by the several exposure estimation methods and analysis models. Figure 4 shows estimated effects on CIMT based on our primary exposure approach (nearest monitor) and Model 2. Increases in predicted $\mathrm{PM}_{2.5}$, OC, EC and sulfur, but not silicon, were associated with increased CIMT; CIMT increases per IQR concentration increases were $14.7 \mu \mathrm{m}(95 \% \mathrm{CI}$ [9.0,20.5]), $35.1 \mu \mathrm{m}$ (26.8,43.3), 9.6 $\mu \mathrm{m}$ (3.6,15.7), $22.7 \mu \mathrm{m}$ $(15.0,30.4)$ and $5.2 \mu \mathrm{m}(-9.8,20.1)$ for $\mathrm{PM}_{2.5}$, OC, EC, sulfur and silicon, respectively. The size of the effect estimates for OC and sulfur was higher than that for EC.
In sensitivity analyses, findings were generally consistent across the three exposure estimation approaches and were largely unchanged when controlling for more covariates in the extended model (Model 3). In addition to controlling for lipid-lowering medications in our primary model, we carried out an analysis restricted to those who reported never having been on statin medications $(n=4,754)$; findings in this subgroup were essentially identical to those in the larger group (results not shown). Effects of adding variables for each metropolitan area to the model (Model 4), effectively removing between-area effects and allowing assessment of only within-area effects, were also examined. Metropolitan area variables could not be added to models

Table 3 Distribution of $\mathrm{PM}_{2.5}$ and $\mathrm{PM}_{2.5}$ component concentrations $\left(\mu \mathrm{g} / \mathrm{m}^{3}\right.$ ) by three estimation approaches

\begin{tabular}{|c|c|c|c|c|c|c|c|c|c|c|}
\hline \multirow[t]{2}{*}{ Approach } & \multicolumn{2}{|c|}{$\mathrm{PM}_{2.5}$} & \multicolumn{2}{|c|}{ EC } & \multicolumn{2}{|c|}{ OC } & \multicolumn{2}{|c|}{ Silicon } & \multicolumn{2}{|c|}{ Sulfur } \\
\hline & Median & IQR & Median & IQR & Median & IQR & Median & IQR & Median & IQR \\
\hline Nearest monitor & 13.66 & 2.340 & 1.36 & 0.825 & 1.93 & 0.62 & 0.11 & 0.074 & 1.30 & 0.409 \\
\hline Inverse-distance weighting (IDW) & 13.69 & 1.314 & 1.32 & 0.570 & 1.92 & 0.31 & 0.12 & 0.039 & 1.26 & 0.425 \\
\hline City-wide average & 13.57 & 1.143 & 1.32 & 0.509 & 2.05 & 0.26 & 0.11 & 0.031 & 1.24 & 0.435 \\
\hline
\end{tabular}

* $\mathrm{PM}_{2.5}$, particulate matter less than or equal to $2.5 \mu \mathrm{m}$ in aerodynamic diameter; $\mathrm{EC}$, elemental carbon; $\mathrm{OC}$, organic carbon. 


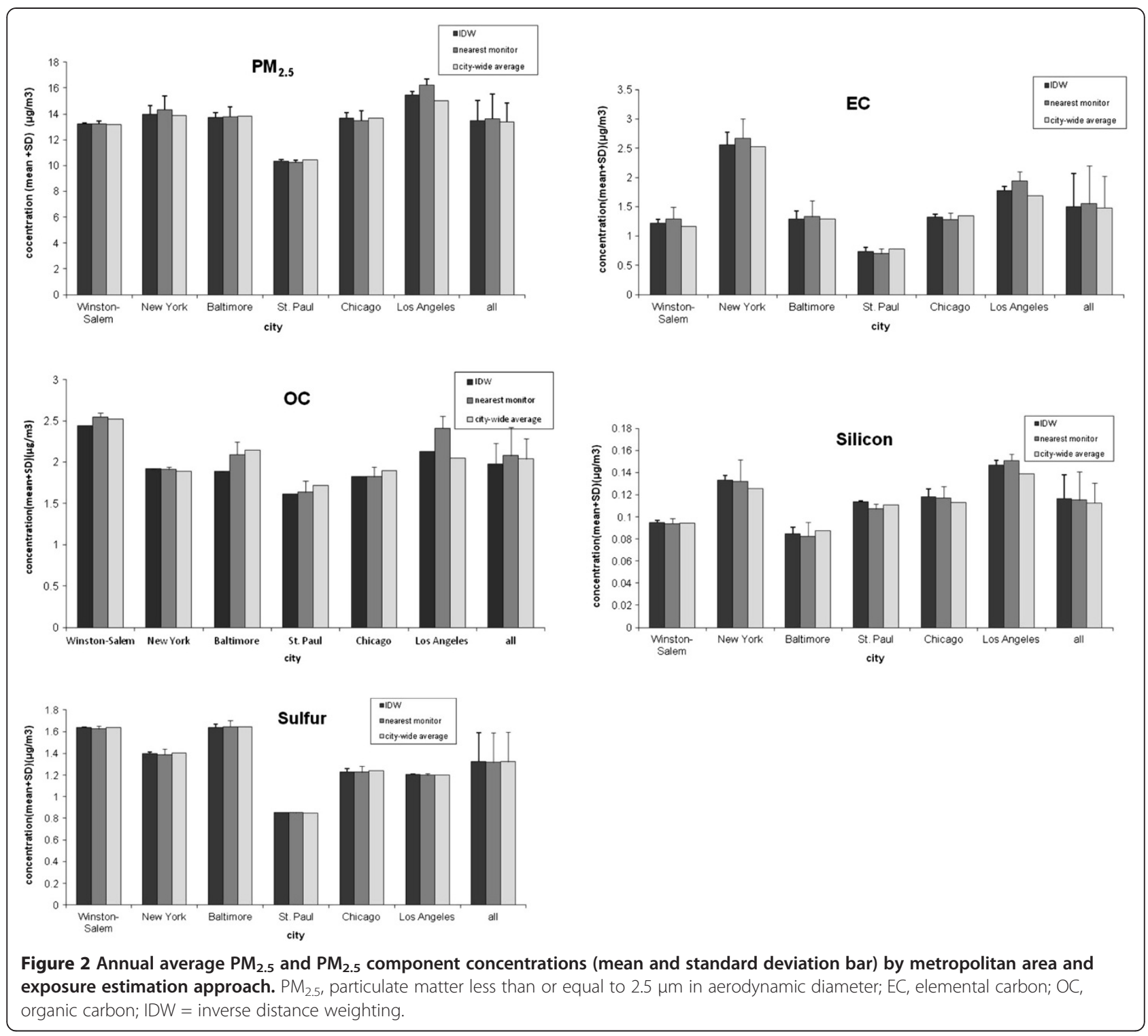

in which city-wide average was used as the exposure metric. Several findings were sensitive to control for area. For our primary exposure method and model, none of associations of $\mathrm{PM}_{2.5}$ and $\mathrm{PM}_{2.5}$ components with CIMT were significant when metropolitan areas were included as covariates in model 2 (Model 4) (Table 4), although the size of the effect estimates for EC and sulfur remained essentially unchanged, and the effect of $\mathrm{PM}_{2.5}$ was only moderately reduced. We also included ultrasound sonographer as an indicator variable in place of metropolitan area in the CIMT models for sonographers who performed at least 10 studies. Since sonographers were unique to study site, this effectively also controlled for study area. Results with sonographer in the CIMT models were essentially no different from those controlling for metropolitan area (results not shown).
For CIMT, estimates from two-pollutant models were examined using nearest monitor and the primary analysis model that included each pair of the $\mathrm{PM}_{2.5}$ components. Only the association of CIMT with OC was not sensitive to inclusion in the model of the other components or total $\mathrm{PM}_{2.5}$ (results not shown).

\section{CAC}

Table 5 shows estimated effects of $\mathrm{PM}_{2.5}$ and $\mathrm{PM}_{2.5}$ components on presence of CAC by the several estimation methods and models. Figure 4 shows estimated effects on presence of CAC based on our primary exposure approach (nearest monitor) and Model 2. For this model, there were no statistically significant associations between presence of CAC and $\mathrm{PM}_{2.5}$ or $\mathrm{PM}_{2.5}$ components. In sensitivity analyses, using IDW or city-wide average, presence 

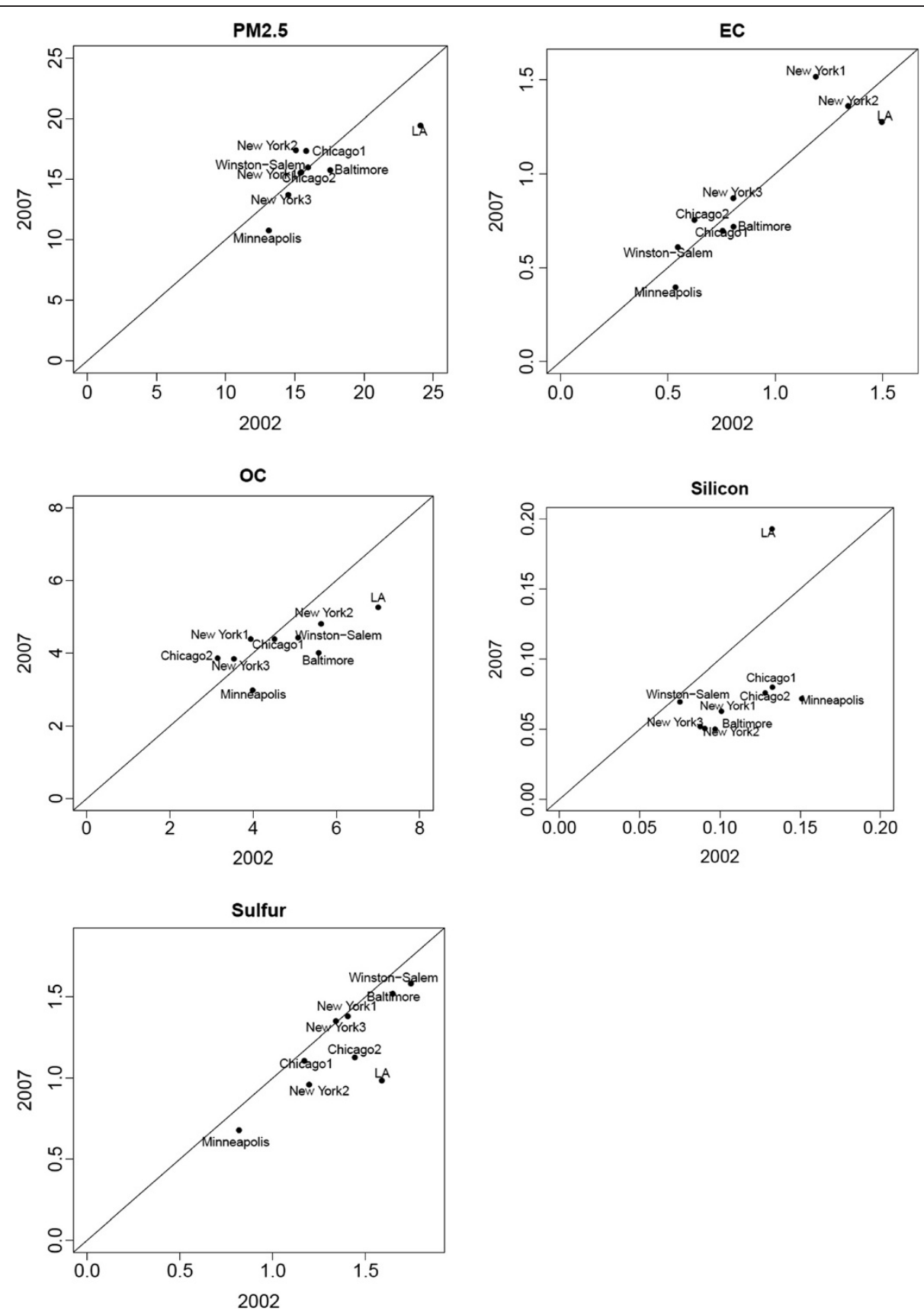

Figure 3 Correspondence of mean $\mathrm{PM}_{2.5}$ and $\mathrm{PM}_{2.5}$ component concentrations in 2002 and 2007 from CSN monitoring sites in the MESA areas. $\mathrm{PM}_{2.5}=$ particulate matter less than or equal to $2.5 \mu \mathrm{m}$ in aerodynamic diameter; $\mathrm{EC}=$ elemental carbon; $\mathrm{OC}=$ organic carbon. Correlation coefficients for 2002 and 2007 values: PM $_{2.5}$ (0.74), EC (0.91), OC (0.72), silicon (0.46), sulfur (0.79).

of CAC was negatively associated with EC in Model 2 and in Model 3 with the extended set of covariates. With adjustment for metropolitan region (Model 4), EC was no longer negatively associated with presence of CAC.

Table 6 shows estimated effects of $\mathrm{PM}_{2.5}$ and $\mathrm{PM}_{2.5}$ components on log-transformed CAC (in those with detectable calcium) by estimation method and models. Figure 4 shows estimated effects on CAC in those with measurable CAC based on our primary exposure and analysis model. For the primary exposure and analysis model, no significant positive association of any PM measure and amount of CAC was observed. In sensitivity analyses, silicon was associated with amount of CAC using city-wide average and IDW, but in the negative direction; this negative association was no longer present after adjustment for city region (Model 4). 
Table 4 CIMT* difference $(\mu \mathrm{m})$ for pollutant IQR increases by analysis model and exposure estimation approach

\begin{tabular}{|c|c|c|c|c|c|}
\hline & $\begin{array}{c}\mathrm{PM}_{2.5}{ }^{*} \\
\text { CIMT difference } \\
(95 \% \mathrm{Cl})\end{array}$ & $\begin{array}{c}\mathrm{EC}^{*} \\
\text { CIMT difference } \\
(95 \% \mathrm{Cl})\end{array}$ & $\begin{array}{c}\text { OC* } \\
\text { CIMT difference } \\
(95 \% \mathrm{Cl})\end{array}$ & $\begin{array}{c}\text { Silicon } \\
\text { CIMT difference } \\
(95 \% \mathrm{Cl})\end{array}$ & $\begin{array}{c}\text { Sulfur } \\
\text { CIMT difference } \\
(95 \% \mathrm{Cl})\end{array}$ \\
\hline \multicolumn{6}{|l|}{ Model $1^{* *}$} \\
\hline Nearest Monitor & $13.7(8.0,19.5)$ & $8.2(2.2,14.2)$ & $36.5(28.3,44.7)$ & $3.1(-11.9,18.0)$ & $22.6(14.9,30.2)$ \\
\hline IDW & $8.8(4.8,12.7)$ & $4.8(0.0,9.5)$ & $25.4(19.9,30.8)$ & $-0.6(-10.2,9.0)$ & $23.8(15.8,31.8)$ \\
\hline City-Wide Average & $7.6(3.7,11.3)$ & $2.6(-1.9,7.1)$ & $21.3(16.4,26.2)$ & $-0.2(-9.9,9.5)$ & $22.9(14.8,31.0)$ \\
\hline \multicolumn{6}{|l|}{ Model $2^{* *}$} \\
\hline Nearest Monitor & $14.7(9.0,20.5)$ & $9.6(3.6,15.7)$ & $35.1(26.8,43.3)$ & $5.2(-9.8,20.1)$ & $22.7(15.0,30.4)$ \\
\hline IDW & $9.6(5.7,13.5)$ & $6.0(1.3,10.8)$ & $24.9(19.4,30.3)$ & $1.3(-8.3,10.9)$ & $24.0(16.0,32.0)$ \\
\hline City-Wide Average & $8.5(4.7,12.3)$ & $3.9(-0.5,8.4)$ & $20.6(15.7,25.5)$ & $1.8(-7.9,11.4)$ & $23.3(15.2,31.4)$ \\
\hline \multicolumn{6}{|l|}{ Model $3^{* *}$} \\
\hline Nearest Monitor & $15.8(9.9,21.7)$ & $10.8(4.6,16.9)$ & $36.5(28.0,44.9)$ & $7.3(-8.0,22.5)$ & $23.9(16.0,31.7)$ \\
\hline IDW & $10.6(6.5,14.6)$ & $7.2(2.3,12.0)$ & $26.9(21.2,32.6)$ & $2.4(-7.4,12.2)$ & $25.4(17.2,33.5)$ \\
\hline City-Wide Average & $9.6(5.7,13.5)$ & $5.0(0.4,9.6)$ & $21.8(16.7,26.9)$ & $2.8(-7.1,12.7)$ & $24.8(16.5,33.1)$ \\
\hline \multicolumn{6}{|l|}{ Model $4^{* *}$} \\
\hline Nearest Monitor & $5.9(-10.3,22.0)$ & $6.3(-11.4,23.8)$ & $-2.3(-26.2,21.5)$ & $-10.1(-41.0,20.6)$ & $27.4(-19.3,73.8)$ \\
\hline IDW & $6.0(-9.8,21.8)$ & $12.1(-11.0,35.0)$ & $* * *$ & $-8.5(-47.2,30.0)$ & $* * *$ \\
\hline
\end{tabular}

*PM 2.5 , particulate matter less than or equal to $2.5 \mu \mathrm{m}$ in aerodynamic diameter; EC, elemental carbon; OC, organic carbon; CIMT, carotid intima-media thickness. **Model 1: covariates include age, gender, race-ethnicity.

Model 2: Model $1+$ total cholesterol, HDL cholesterol, smoking status, hypertension, lipid-lowering medication

Model 3: Model 2 + education, income, waist circumference, body surface area, BMI, BMI ${ }^{2}$, diabetes, LDL, triglycerides.

Model 4: Model $2+$ metropolitan area.

***unstable estimate.

\section{Discussion}

The MESA Air and NPACT air monitoring campaign employed cohort-oriented fixed site monitors in which 2-week measurements of total $\mathrm{PM}_{2.5}$ and $\mathrm{PM}_{2.5}$ components were obtained. Using our primary approach to estimating exposure (nearest monitor) and our primary health effects model, there were cross-sectional associations of CIMT with OC, EC, and sulfur, as well as with total $\mathrm{PM}_{2.5}$, but not with silicon. The strongest associations were for
$\mathrm{OC}$ and sulfur. The associations were reasonably robust to exposure estimation method (nearest monitor, IDW and city-wide mean) and to adjustment for additional potential risk factors and other $\mathrm{PM}_{2.5}$ components, but not to control for metropolitan area. These associations with CIMT, especially that for $\mathrm{OC}$, were therefore primarily related to exposure differences between metropolitan areas.

Neither presence of CAC nor extent of CAC was positively associated with $\mathrm{PM}_{2.5}$, $\mathrm{OC}$, or any other $\mathrm{PM}_{2.5}$

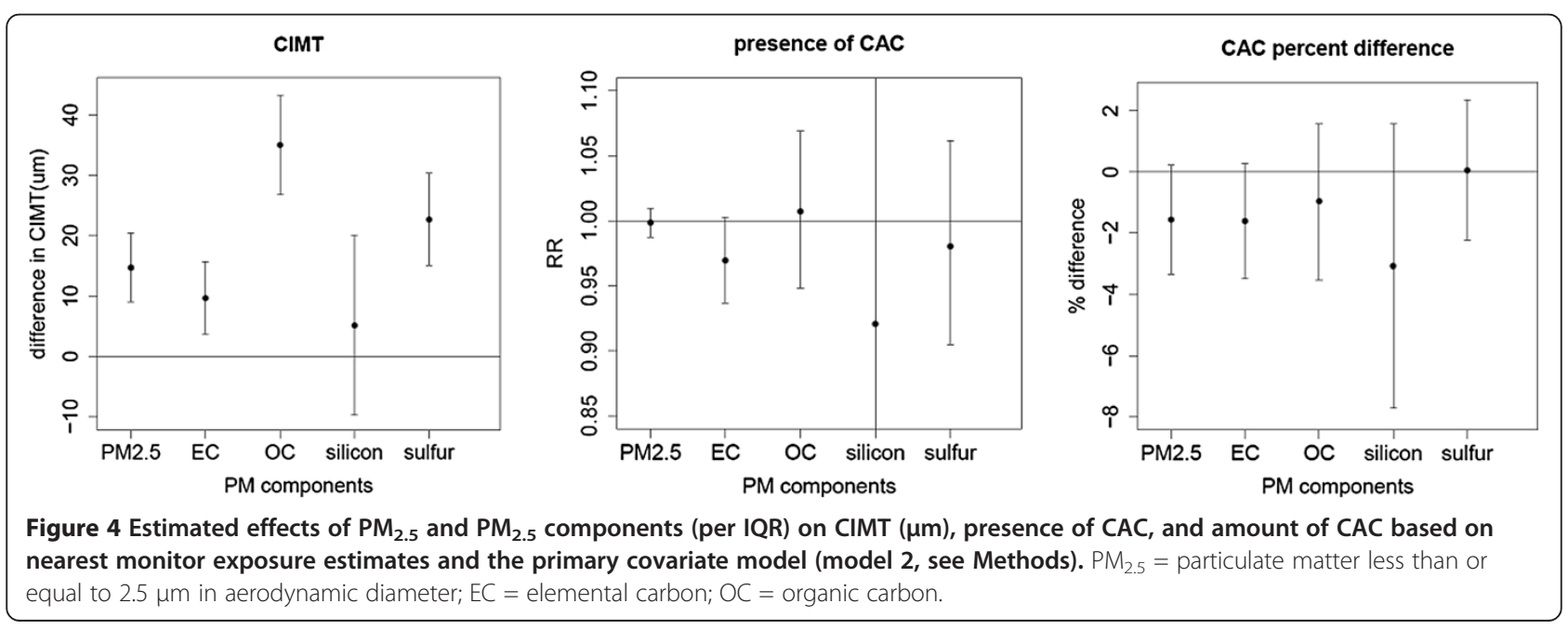


Table 5 CAC* relative risk (RR) for pollutant IQR increases by analysis model and exposure estimation approach

\begin{tabular}{|c|c|c|c|c|c|}
\hline & $\begin{array}{c}\mathrm{PM}_{2.5}{ }^{*} \\
\mathrm{RR}(95 \% \mathrm{Cl})\end{array}$ & $\begin{array}{c}\mathrm{EC}^{*} \\
\mathrm{RR}(95 \% \mathrm{Cl})\end{array}$ & $\begin{array}{c}\text { OC* } \\
\text { RR }(95 \% \mathrm{Cl})\end{array}$ & $\begin{array}{c}\text { Silicon } \\
\text { RR }(95 \% \mathrm{Cl})\end{array}$ & $\begin{array}{c}\text { Sulfur } \\
\text { RR }(95 \% \mathrm{Cl})\end{array}$ \\
\hline \multicolumn{6}{|l|}{ Model $1^{* *}$} \\
\hline Nearest Monitor & $1.00(0.99,1.01)$ & $0.96(0.93,0.99)$ & $1.03(0.96,1.09)$ & $0.84(0.33,2.14)$ & $0.98(0.91,1.07)$ \\
\hline IDW & $0.99(0.98,1.01)$ & $0.95(0.91,0.99)$ & $0.98(0.90,1.06)$ & $0.49(0.16,1.53)$ & $0.98(0.90,1.06)$ \\
\hline City-Wide Average & $0.99(0.98,1.00)$ & $0.94(0.90,0.98)$ & $1.01(0.09,1.55)$ & $0.37(0.09,1.55)$ & $0.97(0.89,1.05)$ \\
\hline \multicolumn{6}{|l|}{ Model $2^{* *}$} \\
\hline Nearest Monitor & $1.00(0.99,1.01)$ & $0.97(0.94,1.00)$ & $1.01(0.95,1.07)$ & $0.92(0.37,2.32)$ & $0.98(0.90,1.06)$ \\
\hline IDW & $1.00(0.98,1.01)$ & $0.96(0.92,1.00)$ & $0.96(0.89,1.04)$ & $0.64(0.21,1.96)$ & $0.97(0.90,1.05)$ \\
\hline City-Wide Average & $0.99(0.98,1.01)$ & $0.95(0.91,0.99)$ & $0.99(0.91,1.08)$ & $0.51(0.12,2.09)$ & $0.97(0.89,1.05)$ \\
\hline \multicolumn{6}{|l|}{ Model $3^{* *}$} \\
\hline Nearest Monitor & $1.00(0.99,1.01)$ & $0.97(0.94,1.01)$ & $1.03(0.97,1.09)$ & $1.02(0.39,2.64)$ & $0.99(0.91,1.07)$ \\
\hline IDW & $1.00(0.99,1.01)$ & $0.96(0.92,1.00)$ & $0.99(0.91,1.07)$ & $0.70(0.22,2.22)$ & $0.98(0.90,1.06)$ \\
\hline City-Wide Average & $1.00(0.98,1.01)$ & $0.96(0.91,0.99)$ & $1.01(0.93,1.10)$ & $0.57(0.13,2.44)$ & $0.97(0.90,1.06)$ \\
\hline \multicolumn{6}{|l|}{ Model $4^{* *}$} \\
\hline Nearest Monitor & $1.01(0.98,1.05)$ & $1.04(0.94,1.15)$ & $1.08(0.91,1.28)$ & $* * *$ & $1.35(0.79,2.30)$ \\
\hline IDW & $1.02(0.97,1.09)$ & $1.11(0.91,1.34)$ & $* * *$ & $* * *$ & $2.04(0.62,6.66)$ \\
\hline
\end{tabular}

*PM 2.5 , particulate matter less than or equal to $2.5 \mu \mathrm{m}$ in aerodynamic diameter; EC, elemental carbon; OC, organic carbon; CAC, coronary artery calcification. **Model 1: covariates include age, gender, race-ethnicity.

Model 2: Model $1+$ total cholesterol, HDL cholesterol, smoking status, hypertension, lipid-lowering medication.

Model 3: Model 2 + education, income, waist circumference, body surface area, BMI, BMI ${ }^{2}$, diabetes, LDL, triglycerides.

Model 4: Model $2+$ metropolitan area.

*** unstable estimate.

Table 6 Percentage change in CAC* for pollutant IQR increases by analysis model and exposure estimation approach

\begin{tabular}{|c|c|c|c|c|c|}
\hline & $\begin{array}{c}\mathrm{PM}_{2.5}{ }^{*} \\
\% \text { Change }(95 \% \mathrm{Cl})\end{array}$ & $\begin{array}{c}\text { EC* }^{*} \\
\% \text { Change }(95 \% \text { Cl) }\end{array}$ & $\begin{array}{c}\text { OC* }^{*} \\
\% \text { Change }(95 \% \text { Cl) }\end{array}$ & $\begin{array}{c}\text { Silicon } \\
\% \text { Change }(95 \% \mathrm{Cl})\end{array}$ & $\begin{array}{c}\text { Sulfur } \\
\% \text { Change }(95 \% \mathrm{Cl})\end{array}$ \\
\hline \multicolumn{6}{|l|}{ Model $1^{* *}$} \\
\hline Nearest Monitor & $-1.52(-3.31,0.26)$ & $-1.65(-3.54,0.24)$ & $-0.59(-3.14,1.96)$ & $-3.96(-8.62,0.70)$ & $0.61(-1.67,2.89)$ \\
\hline IDW & $-1.00(-2.21,0.21)$ & $-1.26(-2.76,0.24)$ & $-0.61(-2.29,1.08)$ & $-3.14(-6.09,-0.19)$ & $0.70(-1.68,3.08)$ \\
\hline City-Wide Average & $-0.85(-2.02,0.32)$ & $-1.11(-2.52,0.30)$ & $0.19(-1.32,1.70)$ & $-3.41(-6.36,-0.45)$ & $0.66(-1.76,3.07)$ \\
\hline \multicolumn{6}{|l|}{ Model $2^{* *}$} \\
\hline Nearest Monitor & $-1.56(-3.34,0.21)$ & $-1.61(-3.49,0.27)$ & $-0.98(-3.52,1.57)$ & $-3.08(-7.73,1.58)$ & $0.05(-2.22,2.33)$ \\
\hline IDW & $-1.03(-2.23,0.17)$ & $-1.22(-2.71,0.28)$ & $-0.86(-2.54,0.83)$ & $-2.52(-5.47,0.43)$ & $0.12(-2.25,2.50)$ \\
\hline City-Wide Average & $-0.63(-1.84,0.58)$ & $-0.83(-2.28,0.63)$ & $0.13(-1.44,1.70)$ & $-3.66(-6.71,-0.61)$ & $1.13(-1.34,3.60)$ \\
\hline \multicolumn{6}{|l|}{ Model $3^{* *}$} \\
\hline Nearest Monitor & $-1.37(-3.22,0.48)$ & $-1.43(-3.37,0.52)$ & $-0.86(-3.51,1.78)$ & $-3.35(-8.18,1.47)$ & $0.58(-1.76,2.92)$ \\
\hline IDW & $-0.89(-2.14,0.37)$ & $-1.06(-2.61,0.49)$ & $-0.90(-2.67,0.86)$ & $-3.07(-6.13,0.00)$ & $0.67(-1.77,3.12$ \\
\hline City-Wide Average & $-0.72(-1.94,0.49)$ & $-0.90(-2.36,0.57)$ & $-0.05(-1.63,1.53)$ & $-3.21(-6.27,-0.14)$ & $0.64(-1.85,3.12)$ \\
\hline \multicolumn{6}{|l|}{ Model $4^{* *}$} \\
\hline Nearest Monitor & $-3.10(-8.08,1.89)$ & $-3.40(-8.76,1.97)$ & $-1.05(-8.03,5.93)$ & $4.13(-5.43,13.68)$ & $-2.32(-16.91,12.27)$ \\
\hline IDW & $-3.78(-8.75,1.19)$ & $-5.42(-12.52,1.69)$ & $* * *$ & $3.24(-8.59,15.07)$ & $8.51(-24.75,41.77)$ \\
\hline
\end{tabular}

${ }^{*} \mathrm{PM}_{2.5}$, particulate matter less than or equal to $2.5 \mu \mathrm{m}$ in aerodynamic diameter; EC, elemental carbon; OC, organic carbon; CAC, coronary artery calcification.

**Model 1: covariates include age, gender, race-ethnicity.

Model 2: Model $1+$ total cholesterol, HDL cholesterol, smoking status, hypertension, lipid-lowering medication.

Model 3: Model 2 + education, income, waist circumference, body surface area, BMI, BMI ${ }^{2}$, diabetes, LDL, triglycerides.

Model 4: Model $2+$ metropolitan area.

***unstable estimate. 
components evaluated. EC and silicon in some models were associated with $\mathrm{CAC}$, but in the negative direction; these associations were sensitive to control for metropolitan area. While CIMT and CAC are highly correlated, they independently predict future cardiovascular events [17], suggesting that each provides somewhat different information on atherosclerosis and cardiovascular disease risk. $\mathrm{CAC}$ is a measure of plaque in the coronary arterial bed while CIMT can be regarded more as a continuous measure of generalized atherosclerosis. Our findings of associations with CIMT but not with CAC are consistent with earlier findings on PM in the MESA cohort [15] and may indicate differential pollutant effects on different vascular beds.

CIMT has been associated cross-sectionally with ambient $\mathrm{PM}_{2.5}$ concentrations estimated using regulatory monitoring data and different approaches to estimating within-urban concentrations. Künzli et al. reported an association in Los Angeles between CIMT and $\mathrm{PM}_{2.5}$ estimated using kriging, with exposure assigned at the zip code level [14]. Diez Roux et al. reported an association between 20-year average $\mathrm{PM}_{2.5}$ concentration and CIMT in this same MESA cohort, with $\mathrm{PM}_{2.5}$ estimated using a spatio-temporal model to predict $\mathrm{PM}_{2.5}$ concentrations at each participant's residence [15]. In this study, as in the current study, there was no association between either presence or extent of CAC and 20-year average $\mathrm{PM}_{2.5}$ [15]. Hoffmann et al., however, reported an association in the Heinz Nixdorf Recall Study cohort in Germany between $\mathrm{PM}_{2.5}$ estimated from a dispersion model and the amount of CAC in the subset of study subjects not working full-time [27]. Unlike our study, the primary focus in these prior studies was on $\mathrm{PM}_{2.5}$ total mass rather than $\mathrm{PM}_{2.5}$ chemical composition, and regulatory monitoring data were employed in estimating $\mathrm{PM}_{2.5}$ concentrations. Analyses involving longitudinal measures of subclinical outcomes and $\mathrm{PM}_{2.5}$ and $\mathrm{PM}_{2.5}$ components will help to assess the validity of our and others' cross-sectional findings.

The cardiovascular effects of long-term exposure to several $\mathrm{PM}_{2.5}$ components have been examined in only one other study. Using the California Teachers Study (CTS) cohort, a prospective cohort of active and former female public school professionals, Ostro et al., in corrected analyses, reported an association of $\mathrm{PM}_{2.5}$ total mass with cardiopulmonary and ischemic heart disease (IHD) mortality; associations of IHD mortality with several $\mathrm{PM}_{2.5}$ components, including $\mathrm{OC}, \mathrm{EC}$, sulfate and silicon, were observed [5]. Here we evaluated the associations between long-term concentrations of both $\mathrm{PM}_{2.5}$ total mass and selected $\mathrm{PM}_{2.5}$ components (EC, OC, silicon, and sulfur) and measures of subclinical atherosclerosis (CIMT and CAC). Of the PM components, the strongest and most consistent associations with CIMT were observed for $\mathrm{OC}$ and sulfur; only the association for $\mathrm{OC}$ was robust to control for the other components.

The choice of the four PM components was influenced by $a$ priori notions that these components reflect different important sources, and together make up the majority of the $\mathrm{PM}_{2.5}$ mass. The $\mathrm{OC}$ carbon fraction reflects direct emissions from fossil fuel and biomass combustion and biogenic sources, as well as contributions from secondary atmospheric reactions [28,29]. In addition to the long-term exposure associations, short-term exposure effects of OC have also been reported in several time series studies. For example, short-term exposure effects on daily cardiovascular mortality were observed in six California counties and in Phoenix, Arizona [30,31]. Metzger et al. reported an association between OC and emergency department visits for cardiovascular disease in Atlanta, Georgia [32]. Modification of short-term $\mathrm{PM}_{2.5}$ cardiovascular effects by long-term concentrations of OC has also been reported [33], although this has not been a consistent observation $[34,35]$.

Sulfur, used as a marker of sulfate, was also associated with CIMT. Sulfate is a secondary aerosol that is formed through photochemical reactions involving sulfur-based compounds, notably sulfur dioxide. Associations of sulfate with cardiopulmonary disease mortality were observed in the ACS study, the Six-Cities study and in the CTS cohort [5]. The sulfate component modified the short-term effect of $\mathrm{PM}_{2.5}$ in one mortality time series study [34]. Also, short-term effects of sulfate have been reported in some studies [36]. It is not clear whether the observed associations with sulfate indicate direct effects of sulfate, or whether these reflect effects of components in the secondary pollutant mix that includes sulfate.

The EC carbon fraction is typically used to reflect diesel emissions and other combustion processes such as wood burning $[37,38]$. We found some associations of EC with CIMT, but these were sensitive to inclusion of any one of the other PM components in the health model (results not shown). EC was negatively associated with presence of CAC, but not after controlling for metropolitan area. Long-term EC was associated with ischemic heart disease mortality in the CTS [5] and was reported to modify short-term $\mathrm{PM}_{2.5}$ effects in one study [35], but not in others [33,34]. Also, short-term EC exposure effects have been reported in time series studies [36].

We found little evidence of an association of silicon with CIMT. In contrast, silicon was, along with several $\mathrm{PM}_{2.5}$ components, associated with cardiopulmonary mortality in the CTS cohort [5]. Silicon is a crustal element that is a large component of soil and resuspended road dust [39]. It may therefore reflect constituents found in road dust, including combustion-based material, brake dust, tire debris, and semivolatile compounds. It may also serve as a general marker for proximity to traffic. Short-term exposure to 
silicon has been associated with cardiovascular effects in a few time-series studies in Arizona and California $[2,30,31,40,41]$. In contrast, in a study of six eastern and Midwestern cities in the U.S., no association between mortality and daily exposure to silicon was seen [42]. Long-term concentrations of silicon did not modify short-term $\mathrm{PM}_{2.5}$ effects in one study [35]. Silicon PM was associated with exacerbation of myocardial ischemia in a dog model of coronary artery disease [39]. While relatively limited exposure contrasts for silicon may have hampered our ability to detect associations with silicon, previously reported findings on silicon effects on cardiovascular outcomes have not been consistent.

All of our measures of PM exposure were based only on the MESA Air fixed ambient air monitors (Figure 1), as we were not able to integrate CSN data into our exposure estimates due to the well-documented poor comparability of monitoring methods, notably for OC and $\mathrm{EC}$, during the monitoring period [43]. Three approaches were employed in assigning exposure to $\mathrm{PM}_{2.5}$ total mass and $\mathrm{PM}_{2.5}$ components. The nearest monitor and the IDW approaches assigned exposure based on the participant's address, as has been done in a few other studies of long-term PM exposure effects on cardiovascular diseases [12,14]. The nearest monitor is assumed to provide a more valid estimate of exposure than city-wide mean, although it is not clear whether it is superior to the IDW approach. Both nearest monitor and IDW estimates attempt to capture some within-city variability in exposure, as opposed to the city-wide mean. We chose, somewhat arbitrarily, the nearest monitor approach as our primary exposure estimation approach, using the IDW and city-wide mean approaches in sensitivity analyses. Our findings were not highly sensitive to the approach to estimating exposure. Future analyses of $\mathrm{PM}_{2.5}$ component effects in the MESA cohort will take advantage of more sophisticated spatiotemporal modeling of pollutants, which will allow for assessment of the impact on the health findings of using these more sophisticated exposure estimates.

A limitation of all of our approaches to estimating exposure is that we only estimate outdoor residential concentrations rather than concentrations to which people are actually exposed. While outdoor concentrations have been shown to be reasonable proxies for indoor concentrations and for personal exposure to particles of outdoor origin $[44,45]$, estimates of outdoor concentrations necessarily mismeasure exposures that are influenced by time-activity patterns that take people away from home, such as work and travel to work. Time-activity studies, however, show that people spend most of their time in or around home [46], justifying the common practice of basing exposure estimates on place of residence. In MESA Air, time-activity data from the entire MESA cohort confirmed that study participants spent most of their time in their homes; the elderly or Chinese participants spent relatively more time in their homes [47]. Future analyses will assess whether our estimates of health effect are modified by incorporation of data collected on time-activity patterns and infiltration of particles indoors.

Adding to the complexity of PM exposure measurement error is the likely differential measurement error across the different $\mathrm{PM}_{2.5}$ components. It is expected that sulfate, with relatively homogeneous concentrations within a metropolitan area, would exhibit less measurement error than OC, for example, whose concentrations vary within an urban area [48]. To the extent that increased exposure measurement error biases effect estimates toward the null [35], it is possible that the association with sulfate is underestimated to a lesser extent than that with OC. In spite of that, we observed that the effect per IQR was higher for OC than any of our $\mathrm{PM}_{2.5}$ components, suggesting that the true association for OC may have been even larger.

Exposure misclassfication could also result from estimating exposure for a time period that is not relevant to the exposure responsible for the observed effect. Exposure was assigned based on one year of monitoring from 2007 to 2008, whereas our endpoint measurements were obtained during the period 2000 to 2002. To address the issue of PM component concentration stability over time, we examined CSN PM 2.5 component data monitoring sites in the six MESA areas for the years 2002 and 2007. There was generally good correlation over that 5-year span (Figure 3). It is therefore reasonable to assume that concentrations in 2000-2002, while likely higher than those in more recent years, were nevertheless highly correlated with them. In the MESA cohort, $\mathrm{PM}_{2.5}$ concentrations were highly correlated over a 20-year period [15], as they were in the American Cancer Society study [49].

Although we included a reasonably comprehensive list of potential individual-level confounder variables in our health effect analyses, it is possible that uncontrolled confounding from unmeasured confounders associated with metropolitan area is present. This motivated control for metropolitan area in Model 4. Our findings were variably sensitive to control for metropolitan area. For example, when study area was added to models using our primary estimation approach (nearest monitor), there was no longer an association of some of the $\mathrm{PM}_{2.5}$ components, especially OC, with CIMT. Because much of the variability in exposure was due to variability between areas, control for metropolitan area substantially reduced exposure variability, which limits our power to detect associations. While we put most interpretive weight on models that did not control for metropolitan area, it may have been preferable to place more weight on findings from models with control for metropolitan area if it 
had been possible to accomplish that without dramatically reducing variability in exposure.

Strengths of this study include the wealth of detailed information on cardiovascular risk factors, the standardized assessment of outcomes, the attempt to incorporate some features of within-city variability in our exposure estimates based on $\mathrm{PM}_{2.5}$ species air monitoring carried out specifically on the MESA cohort, and the assessment of sensitivity of findings to employing three commonly-used approaches for estimating exposure. Future work will employ more sophisticated methods for estimating individual-level exposure to PM components that incorporate land use regression modeling and geostatistical methods, as well as time-activity data. Effects on longitudinal change in CIMT and $C A C$, in addition to the cross-sectional effects described in this report, will also be assessed when those data are available.

\section{Conclusion}

In summary, this is the first study to assess the effect of $\mathrm{PM}_{2.5}$ chemical components on subclinical measures of cardiovascular disease. In this multi-ethnic cohort using the nearest monitor approach to estimating exposure, of the selected $\mathrm{PM}_{2.5}$ components, we found the strongest evidence for cross-sectional associations of OC and sulfur with CIMT. More sophisticated exposure estimation is planned in the MESA cohort, as well as analyses utilizing longitudinal outcome measures, either of which could enhance the validity of future health effect estimates. Evidence such as reported here on the differential health effects of individual PM components should allow for more focused and effective ambient air quality standards aimed at protecting public health.

\section{Abbreviations}

CIMT: Carotid Intima-Media Thickness; CAC: Coronary Artery Calcium; MESA: Multi-Ethnic Study of Atherosclerosis; MESA Air: MESA and Air Pollution; NPACT: National Particle Component Toxicity Initiative;

$\mathrm{PM}_{2.5}$ : Particulate matter $<2.5 \mu \mathrm{m}$ in aerodynamic diameter; EC: Elemental Carbon; OC: Organic Carbon; IQR: Interquartile Range; IDW: Inverse Distance Weighting

\section{Competing interests}

The authors declare that they have no completing interests.

\section{Authors' contributions}

MS carried out the statistical analysis and wrote the draft of the manuscript; JDK assisted in the study design and in drafting the manuscript; SYK assisted with the data analysis; TLV helped design the monitoring network and planned the pollutant laboratory analyses; TRG coordinated the pollutant laboratory analyses; JFP helped design the ultrasound examinations and performed the ultrasound readings; MJB helped design the CT scan examinations; AVDR assisted in study design and analysis; SV assisted in the study design, supervised the data analysis and helped to draft the manuscript. All authors read and approved the final manuscript.

\section{Acknowledgements}

The Multi-Ethnic Study of Atherosclerosis (MESA) is supported by contracts from the National Heart Lung and Blood Institute (N01-HC-95159 through N01-HC-95165 and N01-HC-95169). The Multi-Ethnic Study of Atherosclerosis and Air Pollution (MESA Air) is supported by grant (RD831697) from the U.S.
Environmental Protection Agency Science to Achieve Results program (STAR). The current work is supported by a grant from the Health Effects Institute. MS was supported by a scholarship from the China Scholarship Council (CSC). Support was also provided by USEPA grant (RD-83479601-0). Its contents are solely the responsibility of the grantee and do not necessarily represent the official views of the USEPA. Further, USEPA does not endorse the purchase of any commercial products or services mentioned in the publication.

\section{Author details}

${ }^{1}$ Department of Environmental and Occupational Health Sciences, University of Washington School of Public Health, 4225 Roosevelt Way NE, \#100, Seattle, WA 98105, USA. ²Department of Occupational Health, Tianjin Medical University School of Public Health, Tianjin, China. ${ }^{3}$ Department of Medicine, University of Washington School of Medicine, Seattle, WA, USA. ${ }^{4}$ Department of Epidemiology, University of Washington School of Public Health, Seattle, WA, USA. ${ }^{5}$ Department of Civil and Environmental Engineering, University of Washington College of Engineering, Seattle, WA, USA. ${ }^{6}$ Department of Radiology, Tufts University School of Medicine, Boston, MA, USA.

${ }^{7}$ Department of Medicine, University of California David Gelfen School of Medicine at Los Angeles, Los Angeles, CA, USA. ${ }^{8}$ Department of Epidemiology, University of Michigan School of Public Health, Ann Arbor, MI, USA.

Received: 25 January 2013 Accepted: 24 April 2013

Published: 3 May 2013

\section{References}

1. Brook RD, Rajagopalan S, Pope CA 3rd, Brook JR, Bhatnagar A, Diez Roux AV, Holguin F, Hong Y, Luepker RV, Mittleman MA, Peters A, Siscovick D, Smith SC Jr, Whitsel L, Kaufman JD: Particulate matter air pollution and cardiovascular disease: an update to the scientific statement from the American Heart Association. Circulation 2010, 121:2331-2378.

2. Lipsett MJ, Tsai FC, Roger L, Woo M, Ostro BD: Coarse particles and heart rate variability among older adults with coronary artery disease in the Coachella Valley, California. Environ Health Perspect 2006, 114:1215-1220.

3. Pope CA 3rd, Thun MJ, Namboodiri MM, Dockery DW, Evans JS, Speizer FE, Heath CW Jr: Particulate air pollution as a predictor of mortality in a prospective study of U.S. adults. Am J Respir Crit Care Med 1995, 151:669-674.

4. Dockery DW, Pope CA 3rd, Xu X, Spengler JD, Ware JH, Fay ME, Ferris BG Jr, Speizer FE: An association between air pollution and mortality in six U.S. cities. N Engl J Med 1993, 329:1753-1759.

5. Ostro B, Lipsett M, Reynolds P, Goldberg D, Hertz A, Garcia C, Henderson $K D$, Bernstein L: Long-term exposure to constituents of fine particulate air pollution and mortality: results from the California Teachers Study. Environ Health Perspect 2010, 118:363-369.

6. Abbey DE, Nishino N, McDonnell WF, Burchette RJ, Knutsen SF, Lawrence Beeson W, Yang JX: Long-term inhalable particles and other air pollutants related to mortality in nonsmokers. Am J Respir Crit Care Med 1999, 159:373-382.

7. Filleul L, Rondeau V, Vandentorren S, Le Moual N, Cantagrel A, Annesi-Maesano I, Charpin D, Declercq C, Neukirch F, Paris C, Vervloet D, Brochard P, Tessier JF, Kauffmann F, Baldi I: Twenty five year mortality and air pollution: results from the French PAARC survey. Occup Environ Med 2005, 62:453-460.

8. Finkelstein MM, Jerrett M, Sears MR: Traffic air pollution and mortality rate advancement periods. Am J Epidemiol 2004, 160:173-177.

9. Gehring U, Heinrich J, Kramer U, Grote V, Hochadel M, Sugiri D, Kraft M, Rauchfuss K, Eberwein HG, Wichmann HE: Long-term exposure to ambient air pollution and cardiopulmonary mortality in women. Epidemiology 2006, 17:545-551.

10. Hoek G, Brunekreef B, Goldbohm S, Fischer P, van den Brandt PA: Association between mortality and indicators of traffic-related air pollution in the Netherlands: a cohort study. Lancet 2002, 360:1203-1209.

11. Lipfert FW, Perry HM Jr, Miller JP, Baty JD, Wyzga RE, Carmody SE: The Washington University-EPRI Veterans' cohort mortality study: preliminary results. Inhal Toxicol 2000, 12(Suppl 4):41-73.

12. Miller KA, Siscovick DS, Sheppard L, Shepherd K, Sullivan JH, Anderson GL, Kaufman JD: Long-term exposure to air pollution and incidence of cardiovascular events in women. N Engl J Med 2007, 356:447-458. 
13. Pope CA 3rd, Burnett RT, Thun MJ, Calle EE, Krewski D, Ito K, Thurston GD: Lung cancer, cardiopulmonary mortality, and long-term exposure to fine particulate air pollution. JAMA 2002, 287:1132-1141.

14. Kunzli N, Jerrett M, Mack WJ, Beckerman B, LaBree L, Gilliland F, Thomas D, Peters J, Hodis HN: Ambient air pollution and atherosclerosis in Los Angeles. Environ Health Perspect 2005, 113:201-206.

15. Diez Roux AV, Auchincloss AH, Franklin TG, Raghunathan T, Barr RG, Kaufman J, Astor B, Keeler J: Long-term exposure to ambient particulate matter and prevalence of subclinical atherosclerosis in the Multi-Ethnic Study of Atherosclerosis. Am J Epidemiol 2008, 167:667-675.

16. Hoffmann B, Moebus S, Kroger K, Stang A, Mohlenkamp S, Dragano N, Schmermund A, Memmesheimer M, Erbel R, Jockel KH: Residential exposure to urban air pollution, ankle-brachial index, and peripheral arterial disease. Epidemiology 2009, 20:280-288.

17. Folsom AR, Kronmal RA, Detrano RC, O'Leary DH, Bild DE, Bluemke DA, Budoff MJ, Liu K, Shea S, Szklo M, Tracy RP, Watson KE, Burke GL: Coronary artery calcification compared with carotid intima-media thickness in the prediction of cardiovascular disease incidence: the Multi-Ethnic Study of Atherosclerosis (MESA). Arch Intern Med 2008, 168:1333-1339.

18. Bild DE, Bluemke DA, Burke GL, Detrano R, Diez Roux AV, Folsom AR, Greenland P, Jacob DR Jr, Kronmal R, Liu K, Nelson JC, O'Leary D, Saad MF, Shea S, Szklo M, Tracy RP: Multi-Ethnic Study of Atherosclerosis: objectives and design. Am J Epidemiol 2002, 156:871-881.

19. Kaufman JD, Adar SD, Allen RW, Barr RG, Budoff MJ, Burke GL, Casillas AM, Cohen MA, Curl CL, Daviglus ML, Diez Roux AV, Jacobs DR Jr, Kronmal RA, Larson TV, Liu SL, Lumley T, Navas-Acien A, O'Leary DH, Rotter Jl, Sampson PD, Sheppard L, Siscovick DS, Stein JH, Szpiro AA, Tracy RP: Prospective study of particulate air pollution exposures, subclinical atherosclerosis, and clinical cardiovascular disease: the Multi-Ethnic Study of Atherosclerosis and Air Pollution (MESA Air). Am J Epidemiol 2012, 176:825-837.

20. Polak JF, Wong Q, Johnson WC, Bluemke DA, Harrington A, O'Leary DH, Yanez ND: Associations of cardiovascular risk factors, carotid intimamedia thickness and left ventricular mass with inter-adventitial diameters of the common carotid artery: the Multi-Ethnic Study of Atherosclerosis (MESA). Atherosclerosis 2011, 218:344-349.

21. Carr JJ, Nelson JC, Wong ND, McNitt-Gray M, Arad Y, Jacobs DR Jr, Sidney S, Bild DE, Williams OD, Detrano RC: Calcified coronary artery plaque measurement with cardiac $C T$ in population-based studies: standardized protocol of Multi-Ethnic Study of Atherosclerosis (MESA) and Coronary Artery Risk Development in Young Adults (CARDIA) study. Radiology 2005, 234:35-43.

22. Agatston AS, Janowitz WR, Hildner FJ, Zusmer NR, Viamonte M Jr, Detrano R: Quantification of coronary artery calcium using ultrafast computed tomography. J Am Coll Cardiol 1990, 15:827-832.

23. Cohen MA, Adar SD, Allen RW, Avol E, Curl CL, Gould T, Hardie D, Ho A, Kinney P, Larson TV, Sampson P, Sheppard L, Stukovsky KD, Swan SS, Liu LJ, Kaufman JD: Approach to estimating participant pollutant exposures in the Multi-Ethnic Study of Atherosclerosis and Air Pollution (MESA Air). Environ Sci Technol 2009, 43:4687-4693.

24. Lumley T, Kronmal R, Ma S: Relative Risk Regression in Medical Research: Models, Contrasts, Estimators, and Algorithms. In UW Biostatistics Working Paper Series. 2006. Available at: http://biostats.bepress.com/uwbiostat/paper293/.

25. Third Report of the National Cholesterol Education Program (NCEP): Expert panel on detection, evaluation, and treatment of high blood cholesterol in adults (adult treatment panel III) final report. Circulation 2002, 106:3143-3421.

26. R Development Core Team: $R$ : a language and environment for statistical computing, 2.12, 2 ed. Vienna, Austria: R Foundation for Statistical Computing; 2011.

27. Hoffmann B, Moebus S, Mohlenkamp S, Stang A, Lehmann N, Dragano N, Schmermund A, Memmesheimer M, Mann K, Erbel R, Jockel KH: Residential exposure to traffic is associated with coronary atherosclerosis. Circulation 2007, 116:489-496.

28. Lewis CW, Norris GA, Conner TL, Henry RC: Source apportionment of Phoenix $\mathrm{PM}_{2.5}$ aerosol with the UNMIX receptor model. J Air Waste Manag Assoc 2003, 53:325-338.

29. Maykut NN, Lewtas J, Kim E, Larson TV: Source apportionment of $\mathrm{PM}_{2.5}$ at an urban IMPROVE site in Seattle, Washington. Environ Sci Technol 2003, 37:5135-5142

30. Mar TF, Norris GA, Koenig JQ, Larson TV: Associations between air pollution and mortality in Phoenix, 1995-1997. Environ Health Perspect 2000, 108:347-353.
31. Ostro B, Feng WY, Broadwin R, Green S, Lipsett M: The effects of components of fine particulate air pollution on mortality in California: results from CALFINE. Environ Health Perspect 2007, 115:13-19.

32. Metzger KB, Tolbert PE, Klein M, Peel JL, Flanders WD, Todd K, Mulholland $J$ A, Ryan PB, Frumkin H: Ambient air pollution and cardiovascular emergency department visits. Epidemiology 2004, 15:46-56.

33. Zanobetti A, Franklin M, Koutrakis P, Schwartz J: Fine particulate air pollution and its components in association with cause-specific emergency admissions. Environ Health 2009, 8:58.

34. Franklin $M$, Koutrakis $P$, Schwartz $P$ : The role of particle composition on the association between $\mathrm{PM}_{2.5}$ and mortality. Epidemiology 2008, 19:680-689.

35. Zeger SL, Thomas D, Dominici F, Samet JM, Schwartz J, Dockery D, Cohen A: Exposure measurement error in time-series studies of air pollution: concepts and consequences. Environ Health Perspect 2000, 108:419-426.

36. Sarnat JA, Marmur A, Klein M, Kim E, Russell AG, Sarnat SE, Mulholland JA, Hopke PK, Tolbert PE: Fine particle sources and cardiorespiratory morbidity: an application of chemical mass balance and factor analytical source-apportionment methods. Environ Health Perspect 2008, 116:459-466.

37. Schauer Jj: Evaluation of elemental carbon as a marker for diesel particulate matter. J Expo Anal Environ Epidemiol 2003, 13:443-453.

38. Abu-Allaban M, Rogers CF, Gertler AW: A quantitative description of vehicle exhaust particle size distributions in a highway tunnel. J Air Waste Manag Assoc 2004, 54:360-366

39. Wellenius GA, Coull BA, Godleski JJ, Koutrakis P, Okabe K, Savage ST, Lawrence JE, Murthy GG, Verrier RL: Inhalation of concentrated ambient air particles exacerbates myocardial ischemia in conscious dogs. Environ Health Perspect 2003, 111:402-408.

40. Batalha JR, Saldiva PH, Clarke RW, Coull BA, Stearns RC, Lawrence J, Murthy GG, Koutrakis P, Godleski Jj: Concentrated ambient air particles induce vasoconstriction of small pulmonary arteries in rats. Environ Health Perspect 2002, 110:1191-1197.

41. Cavallari JM, Eisen EA, Fang SC, Schwartz J, Hauser R, Herrick RF, Christiani DC: $\mathrm{PM}_{2.5}$ metal exposures and nocturnal heart rate variability: a panel study of boilermaker construction workers. Environ Health 2008, 7:36.

42. Laden F, Neas LM, Dockery DW, Schwartz J: Association of fine particulate matter from different sources with daily mortality in six U.S. cities. Environ Health Perspect 2000, 108:941-947.

43. Chow JC, Watson JG, Chen LWA, Rice J, Frank NH: Quantification of $\mathbf{P M}_{2.5}$ organic carbon sampling artifacts in US networks. Atmos Chem Phys 2010, 10:5223-5239.

44. Janssen NA, Hoek G, Brunekreef B, Harssema H, Mensink I, Zuidhof A Personal sampling of particles in adults: relation among personal, indoor, and outdoor air concentrations. Am J Epidemiol 1998, 147:537-547.

45. Dockery DW, Spengler JD: Indoor-outdoor relationships of respirable sulfates and particles. Atmos Environ 1981, 15:335-343.

46. Leech JA, Nelson WC, Burnett RT, Aaron S, Raizenne ME: It's about time: a comparison of Canadian and American time-activity patterns. J Expo Anal Environ Epidemiol 2002, 12:427-432.

47. Curl CL, Adar SD, Cohen MA, Hinckley-Stukovsky K, Allen R, Mancera-Cuevas K, Nunn CL, Castro C, Christman C, Dwight C, Kaufman JD: An evaluation of time-location data: the Multi-Ethnic Study of Atherosclerosis and Air Pollution (MESA Air). Epidemiology 2008, 19:S328.

48. Ito K, Xue N, Thurston G: Spatial variation of $\mathrm{PM}_{2.5}$ chemical species and source-apportioned mass concentrations in New York City. Atmos Environ 2004, 38:5269-5282.

49. Abrahamowicz M, Schopflocher T, Leffondre $K$, du Berger R, Krewski D: Flexible modeling of exposure-response relationship between long-term average levels of particulate air pollution and mortality in the American Cancer Society study. J Toxicol Environ Health A 2003, 66:1625-1654.

\section{doi:10.1186/1476-069X-12-39}

Cite this article as: Sun et al:: Particulate matter components and subclinical atherosclerosis: common approaches to estimating exposure in a Multi-Ethnic Study of Atherosclerosis cross-sectional study. Environmental Health 2013 12:39. 